\title{
Predictors of mortality for patients admitted to the intensive care unit with obstructing septic stones
}

Uday Mann'; Kunal Jain"; Rachel Wong ${ }^{1}$; Zack Li ${ }^{1}$; Amanda Eng ${ }^{1}$; Ruben BlachmanBraun $^{2}$; Premal Patel ${ }^{1}$

${ }^{1}$ Section of Urology, Department of Surgery, University of Manitoba, Winnipeg, MB, Canada;

${ }^{2}$ Department of Urology, University of Miami, Miami, FL, United States

Acknowledgements: The authors would like to sincerely thank Ms. Julie Mojica of Critical Care/Medicine Info System \& Research at Winnipeg Regional Health Authority for her assistance with the Critical Care database.

Cite as: Mann U, Jain K, Wong R, et al. Predictors of mortality for patients admitted to the intensive care unit with obstructing septic stones. Can Urol Assoc J 2021 May 11; Epub ahead of print. http://dx.doi.org/10.5489/cuaj.7118

Published online May 11, 2021

Correspondence: Dr. Premal Patel, Section of Urology, Department of Surgery, University of Manitoba, Winnipeg, MB, Canada; ppatel5@hsc.mb.ca

$* * *$

\section{Abstract}

Introduction: Patients diagnosed with septic stone are at significant risk of morbidity and mortality should source control through drainage be delayed, and they are often admitted to intensive care units (ICU) for hemodynamic support. The purpose of this study was to determine patient factors that may predict mortality in patients admitted to ICU with septic stone, particularly whether rural patients at a greater distance from a tertiary care center were at greater risk of mortality given the inherent delay in intervention.

Methods: The Manitoba Intensive Care Unit prospective registry began in 1999 and includes all patients admitted to ICU across Manitoba. Baseline characteristics, such as age, gender, vital signs, creatinine, Charlson comorbidity index (CCI), mortality outcomes, and location of residency were obtained for those admitted to ICU for septic stone. Association between death and clinical/demographic variable was performed with adjusted multivariable logistical regression analysis.

Results: A total of 342 patients admitted to the ICU were analyzed with a mean age of $63.5 \pm 15.5$ years. Baseline characteristics were similar between groups $(p>0.05)$. On multivariable adjusted logistical regression, the presence of acute kidney injury (AKI) $(p<0.001)$ and intubation $(p<0.001)$ were associated with mortality. There was no difference in mortality attributable to location of residency, vital signs, or CCI. 
Conclusions: Among patients admitted to the ICU for septic stones in Manitoba, we demonstrate an association between AKI and intubation with mortality. Other factors, such as whether patients were from a rural region and baseline patient characteristics, were not predictive of mortality.

\section{Introduction}

Urosepsis associated with a urinary tract obstructing calculus, or septic stone, is a urological emergency. In addition to antibiotic administration, urgent decompression of the urinary tract with an indwelling ureteric stent or a percutaneous nephrostomy tube is critical. Should these interventions be delayed, patients risk complications including sepsis, septic shock, and disseminated intravascular coagulopathy. These complications may result in admission to an intensive care unit (ICU) for hemodynamic support and may ultimately lead to severe morbidity, and even death. ${ }^{[1-4]}$

Scant literature concerning outcomes for patients admitted to ICUs with septic stone exists. Previous work has shown that septic stone patients with decreasing platelet counts and serum albumin levels may imminently require ICU admission. ${ }^{[5]}$ Following ICU admission, elective ureteroscopic lithotripsy for definitive treatment has been shown to be safe and efficacious, regardless of the method for emergency decompression that was initially used. ${ }^{[6]}$ However, no study has compared factors of septic stone patients requiring ICU admission at presentation with their subsequent morbidity and mortality.

Our study aimed to investigate predictors of mortality for patients admitted to ICUs with septic stone. We hypothesised that patients with increased age, increased WBC, and increased creatinine $(\mathrm{Cr})$ at presentation would have higher rates of mortality. Additionally, the province of Manitoba has a very large geographic catchment area, with only one major city providing urgent urologic intervention. Given Manitoba's large geographic area, transfer of patients to a tertiary care centre with septic stones is required for urinary tract decompression. Therefore, we hypothesized that rural patients were at greater risk of mortality given the inherent delay in intervention (i.e. hospital transfer).

\section{Methods}

The Manitoba Intensive Care Unit prospective registry began in 1999 and includes all patients admitted to ICUs across Manitoba, Canada. Baseline characteristics such as age, gender, creatinine, Charlson comorbidity index (CCI), mortality outcomes, and location of residence were obtained for those admitted to ICU for septic stones from January $1^{\text {st }}, 1999$, to November $1^{\text {st }}, 2019$. Vital signs collected and analyzed were at initial patient presentation. Acute kidney injury (AKI) was defined as per Kidney Disease: Improving Global Outcomes (KDIGO) Guidelines for acute kidney injury.

Statistical analysis was performed with SPSS version 24 software for Windows. A p-value $<0.05$ was considered statistically significant. After determining data 
distribution, mean \pm standard deviation or medians, and interquartile ranges [IQR: 2575], Student T or U Mann-Whitney tests were used to compare continuous variables between groups. Categorical variables were presented as absolute values and frequencies. They were analyzed with a Chi-square or Fisher's exact test, as indicated. An exploratory analysis comparing patients living in a rural and urban areas was subsequently performed. Urban was defined as postal codes starting with R2, R3, or R4 (urban Winnipeg) and rural was defined as all other postal codes within Manitoba. In the overall population, a univariate and a multivariate-adjusted logistic regression analysis was performed to calculate the risk of mortality using odds ratios (OR) and the $95 \%$ confidence interval $(95 \% \mathrm{CI})$, in accordance with clinical and demographic variables.

\section{Results}

A total of 342 patients admitted to ICUs were analyzed with a mean age of $63.5 \pm 15.5$. Of those, $141(41.2 \%)$ were males, $32(9.4 \%)$ had hypothermia $\left(<36{ }^{\circ} \mathrm{C}\right)$ on admission, $114(33.3 \%)$ were febrile $\left(>38^{\circ} \mathrm{C}\right)$ on admission, $70(20.5 \%)$ were intubated, and 85 (24.9\%) had acute kidney injury (AKI). Patients who died during hospitalization had higher rates of hypothermia on ICU admission [survived: 22 (7.4\%) vs. deceased: 10 $(23.3 \%)$ ], worse Glasgow coma scale (GCS; survived: 15 [11 - 15] vs. deceased: 10 [5 $15] ; \mathrm{p}<0.001)$, worse tachycardia $(\mathrm{p}=0.036)$, required intubation $(\mathrm{p}<0.001)$, and were more likely to have had an AKI $(\mathrm{p}<0.001)$ (Table 1$)$.

For the exploratory analysis, 206 patients were included, as information for residential area was obtained in 68 urban residents and 138 rural residents. Clinical and demographic variables between both groups were similar $(\mathrm{p}>0.05)$, with no difference in mortality rates (urban $=12(17.6 \%)$ vs. rural $16(11.6 \%) ; p=0.233)$ (Table 2).

On univariate analysis, hypothermia, AKI, and intubation were significantly associated with increased mortality $(\mathrm{p}<0.05)$. On multivariate analysis, the presence of AKI $(\mathrm{OR}=4.620,95 \% \mathrm{CI}: 2.103-10.150 ; \mathrm{p}<0.001)$ and intubation $((\mathrm{OR}=5.005$, $95 \% \mathrm{CI}: 1.945-12.878 ; \mathrm{p}=0.001)$ were associated with an increased risk of mortality. (Table 3)

\section{Discussion}

An obstructing urinary calculus with a concomitant urinary traction infection is a common urological emergency with a reported incidence of 20.1 per 100,000 adults per year, ${ }^{[3]}$ an ICU admission rate of $35 \%,{ }^{[6]}$ and a mortality of 0 to $2 \% .{ }^{[1,5]}$ While previous literature has demonstrated biochemical factors predictive of ICU admission, we believe that this is the first study to show that septic stone patients presenting with AKI (and hypothermia on univariate analysis) and requiring intubation were at an increased risk of mortality during their hospitalization.

Our results add to the existing literature on clinical factors that may influence mortality in septic stone patients. Patients that required intubation either due to respiratory failure or alternated mental status, had a significant mortality risk $(\mathrm{OR}=$ $5.005, \mathrm{p}=0.001)$. These findings are consistent with the literature, suggesting that 
patients with sepsis, worsening neurologic function, ${ }^{[7,8]}$ and acute respiratory distress syndrome ${ }^{[9]}$ had increased morbidity and mortality. Furthermore, sepsis-associated AKI was a common complication in our cohort $(24.9 \%)$, and this is a well-known complication associated with high mortality. ${ }^{[10]}$ While neither result is surprising in itself, as a natural course of a patient progressing to intubation or end-organ system failure is concerning for worse outcomes, our findings should alert clinicians to treat these patients more aggressively upon presentation. Two clinical scoring systems (Sequential [Sepsis-related] Organ Failure Assessment (SOFA) and quickSOFA) have been proposed to predict ICU admission and in-hospital mortality in patients with septic stone.[11] These scoring systems include vital parameters and laboratory results. Our findings support the use of serum creatinine and may add credence to include intubation as a disease-specific factor.

Other factors, such as location of residence and baseline patient characteristics, were not predictive of mortality. In the exploratory analysis in which we compare the 68 patients (33\%) known to live in urban area against the $138(67 \%)$ patients that reside in rural regions, there was not a significant mortality increase in patients that reside in rural regions $(\mathrm{OR}=0.477,95 \% \mathrm{CI}: 0.183-1.244, \mathrm{p}=0.130)$. This study is in line with our previous findings, in which survival among patients with Fournier's gangrene was similar between rural and urban Manitoba residential locations. ${ }^{[12]}$ On the other hand, in other world regions, it has been shown that there is a disparity in sepsis survival among geographical locations, such as rural Midwestern United States, in which rural hospital bypass is independently associated with increased mortality. ${ }^{[13]}$ The similar survival rates among patients with septic stone in ICUs in Manitoba may be explained by how we defined rural and urban regions, the efficacy of a single-tier healthcare system, geographic, political, or socioeconomic factors that are currently unclear. This finding warrants further research.

Our study was limited by biases inherent in a retrospective review of a database. Although our reported mortality was high (12.6\%), it is important to emphasize that our cohort only included patients that required ICU admission. Additionally, we classified location by rural and urban, rather than distance from nearest hospital. In Manitoba, there is large heterogeneity in rural settings, where some communities are supplied by a primary or secondary level hospital with reasonable land transport access, whereas other communities are only supplied by nursing stations with requirements for air transport for access. Accounting for these differences more in-depth may have provided a result more consistent with our hypothesis and existing literature. Additionally, our study did not account for patients who had initially presented to a rural hospital and were then transferred to a tertiary care hospital, as opposed to patients who presented directly to a tertiary care hospital. Furthermore, while we did not study the association of indwelling ureteric stents versus percutaneous nephrostomy tubes on our outcome, previous studies have shown similar rates of success (98-100\%) and of patients requiring ICU admission post intervention (3-9\%). ${ }^{[14-18]}$ However, more randomized clinical trials with adequate power are needed to help elucidate the optimum management for these patients. Finally, 
our study did not differentiate patients based on the variable of time (i.e. time from symptom onset to decompression); however, a recent study did show that a delay in treatment was associated with worse outcomes. ${ }^{[19]}$

\section{Conclusions}

In summary, intubation and AKI are associated with higher rates of mortality in septic stone patients requiring ICU admission. This information offers clinicians a greater understanding of their patient trajectories. It is also reassuring to note that we did not find any differences in mortality for patients from urban or rural areas, suggesting that equitable quality of care is maintained within our single-tier healthcare system, as it concerns septic stone patients' emergent management, ICU admission, and mortality. Further work is needed to study potential geographic differences on our outcomes.

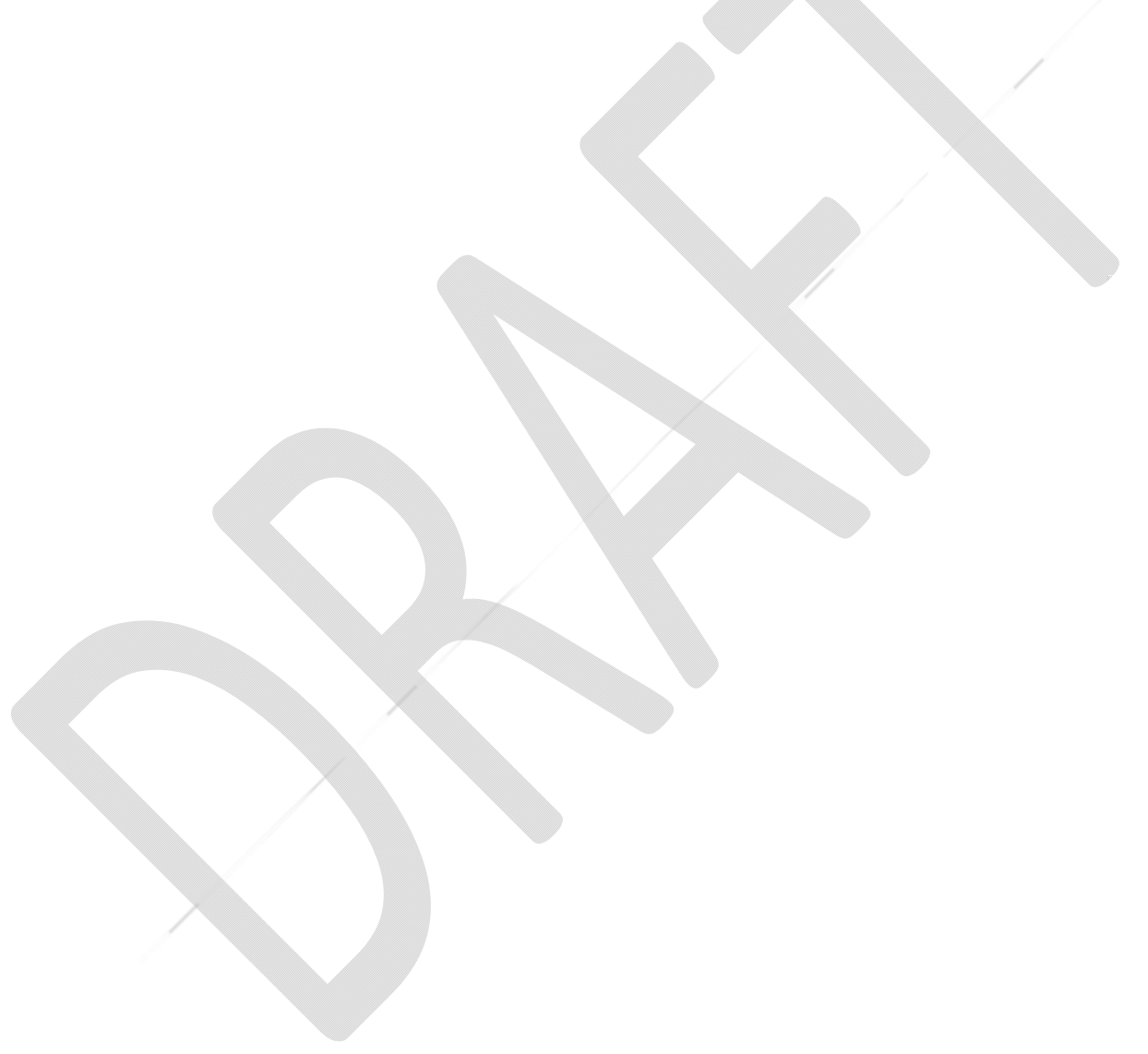




\section{References}

1. Yoshimura K, Utsunomiya N, Ichioka $\mathrm{K}$ et al. Emergency drainage for urosepsis associated with upper urinary tract calculi. J Urol 2005; 173: 458-62.

2. Hamasuna R, Takahashi S, Nagae $H$ et al. Obstructive pyelonephritis as a result of urolithiasis in Japan: diagnosis, treatment and prognosis. Int J Urol 2015; 22: 294-300.

3. Sammon JD, Ghani KR, Karakiewicz PI et al. Temporal trends, practice patterns, and treatment outcomes for infected upper urinary tract stones in the United States. Eur Urol 2013; 64: 85-92.

4. Liang $X$, Huang J, Xing $M$ et al. Risk factors and outcomes of urosepsis in patients with calculous pyonephrosis receiving surgical intervention: a singlecenter retrospective study. BMC Anesthesiol 2019; 19: 61

5. Tambo M, Okegawa T, Shishido T et al. Predictors of septic shock in obstructive acute pyelonephritis. World J Urol 2014; 32:803-11

6. Pietropaolo A, Handry J, Kyriakides R et al. Outcomes of elective ureteroscopy for ureteric stones in patients with prior urosepsis and emergency drainage: prospective study over $5 \mathrm{yr}$ from a tertiary endourology centre. Eur Urol Focus 2020; 6(1): 151-6.

7. Sonneville R, Verdonk F, Rauturier C, et al. Understanding brain dysfunction in sepsis. Ann. Intensive Care 201; 3:15

8. Gofton TE and Young GB. Sepsis-associated encephalopathy. Nat Rev Neurol 2012; 8(10): 557-66.

9. Kim WY, and Hong SB. Sepsis and acute respiratory distress syndrome: recent update. Tuberc Resp Dis (Seoul). 2016; 79(2): 53-7.

10. Peerapornratana S, Manrique-Callibero C, Gomez H et al. Acute kidney injury from sepsis: current concepts, epidemiology, pathophysiology, prevention and treatment. Kidney Int. 2019; 96(5): 1083-99.

11. Fukushima H, Kobayashi M, Kawano K, et al. Performance of quick sequential (sepsis related) and sequential (sepsis related) organ failure assessment to predict mortality in patients with acute pyelonephritis associated with upper urinary tract calculi. J Urol. 2018; 199(6): 1526-33.

12. Wong R, Blachman-Braun R, Mann U, et al. Location of residence and mortality for patients diagnosed with Fournier's gangrene. CUAJ. 2020; 15(5)

13. Mohr N, Harland K, Shane D, et al. Rural patients with severe sepsis or septic shock who bypass rural hospitals have increased mortality: an instrumental variables approach. Crit Care Med. 2017; 45(1): 85-93

14. Flukes S, Hayne D, Kuan M, et al. Retrograde ureteric stent insertion in the management of infected obstructed kidneys. BJU Int. 2015; 115: 31-4.

15. Goldsmith Z, Oredein-McCoy O, Gerber L, et al. Emergent ureteric stent vs percutaneous nephrostomy for obstructive urolithiasis with sepsis: patterns of use and outcomes from a 15-year experience. BJU Int. 2013; 112(2): E122-8.

16. Mokhmalji H, Braun P, Martinez Pollino F, et al. Percutaneous nephrostomy versus ureteral stents for diversion of hydronephrosis caused by stones: a prospective randomized clinical trial. J Urol. 2001; 165(4):1088-92

17. Lee W, Patel U, Patel S, et al. "Emergency percutaneous nephrostomy: results and complications. J Vasc Interv Radiol. 1994; 5(1): 135-9.

18. Yoder I, Lindfors K, and Pfister R. Diagnosis and treatment of pyonephrosis. Radiol Clin North Am. 1984; 22(2): 407-14. 
19. Haas CR, Li G, Hyams ES, Shah O. Delayed Decompression of Obstructing Stones with Urinary Tract Infection is Associated with Increased Odds of Death. J Urol. 2020;204(6):1256-1262.

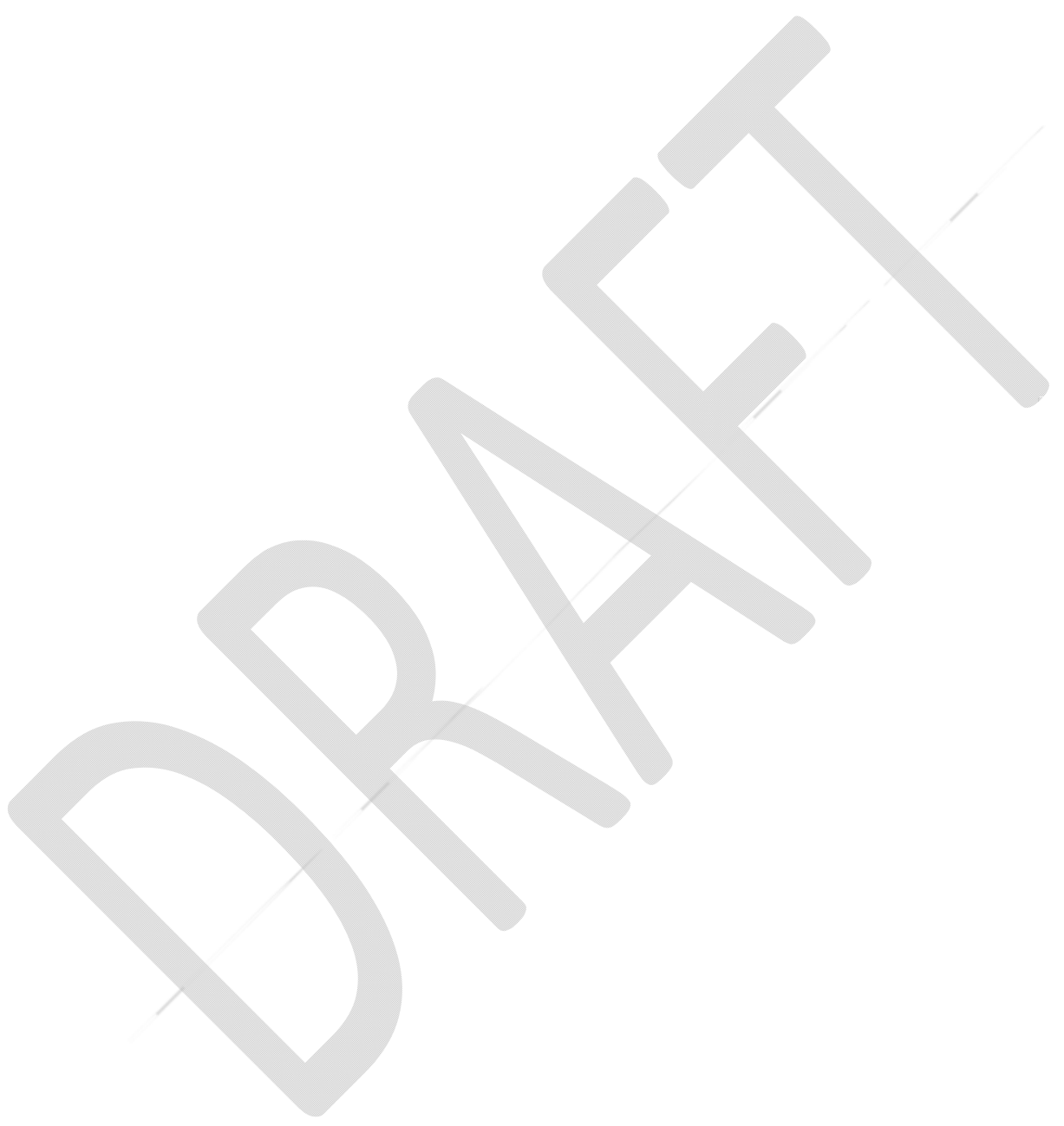


Figures and Tables

\begin{tabular}{|c|c|c|c|c|}
\hline Variable & $\begin{array}{c}\text { Overall } \\
\mathrm{n}=342(100 \%)\end{array}$ & $\begin{array}{c}\text { Survived } \\
\mathrm{n}=299(87.4 \%)\end{array}$ & $\begin{array}{c}\text { Deceased } \\
\mathrm{n}=43(12.6 \%)\end{array}$ & $\mathbf{p}$ \\
\hline Age in years & $63.5 \pm 15.5$ & $63.3 \pm 15.2$ & $64.6 \pm 17.3$ & 0.618 \\
\hline \multicolumn{5}{|l|}{ Sex } \\
\hline Male & $141(41.2 \%)$ & $118(39.5 \%)$ & $23(53.5 \%)$ & \\
\hline Female & $201(58.8 \%)$ & $181(60.5 \%)$ & $20(46.5 \%)$ & 0.081 \\
\hline Temperature $\left({ }^{\circ} \mathrm{C}\right)$ & $37.4(36.5-38.4)$ & $37.5(36.5-38.4)$ & $37.2(36-38.4)$ & 0.117 \\
\hline \multicolumn{5}{|l|}{$\begin{array}{l}\text { Temperature } \\
\text { codified }\end{array}$} \\
\hline$<36{ }^{\circ} \mathrm{C}$ & $32(9.4 \%)$ & $22(7.4 \%)$ & $10(23.3 \%)$ & \\
\hline $36-38^{\circ} \mathrm{C}$ & $196(57.3 \%)$ & $176(58.9 \%)$ & $20(46.5 \%)$ & \\
\hline$>38^{\circ} \mathrm{C}$ & $114(33.3 \%)$ & $101(33.8 \%)$ & $13(30.2 \%)$ & 0.004 \\
\hline $\mathrm{SBP}(\mathrm{mmHg})$ & $80(70-90)$ & $80(70-91)$ & $77(68-88)$ & 0.183 \\
\hline DBP $(\mathrm{mmHg})$ & $46(40-51)$ & $46(40-52)$ & $45(40-50)$ & 0.354 \\
\hline HR (bpm) & $120(105-138)$ & $119(104-135)$ & $127(111-146)$ & 0.036 \\
\hline Total GCS & $15(10-15)$ & $15(11-15)$ & $10(5-15)$ & $<0.001$ \\
\hline \multicolumn{5}{|l|}{ Intubated status } \\
\hline Not intubated & $272(79.5 \%)$ & $249(83.3 \%)$ & $23(53.5 \%)$ & \\
\hline Intubated & $70(20.5 \%)$ & $50(16.75)$ & $20(46.5 \%)$ & $<0.001$ \\
\hline WBC & $19.8(13.3-28.5)$ & $20.4(13.6-29)$ & $17.1(9.8-23.3)$ & 0.022 \\
\hline $\begin{array}{l}\text { Creatinine } \\
(\mu \mathrm{mol} / \mathrm{L})\end{array}$ & $\begin{array}{c}176 \\
(113.8-265.3)\end{array}$ & $173(112-252)$ & $224(132-406)$ & 0.029 \\
\hline \multicolumn{5}{|l|}{ AKI } \\
\hline No AKI & $257(75.1 \%)$ & $238(79.6 \%)$ & $19(44.2 \%)$ & \\
\hline AKI & $85(24.9 \%)$ & $61(20.4 \%)$ & $24(55.8 \%)$ & $<0.001$ \\
\hline Charlson score & $2(0-3)$ & $2(0-3)$ & $2(1-5)$ & 0.121 \\
\hline LOS (in days) & $3.8(1.9-7.6)$ & $3.8(2-7.6)$ & $3.8(1.6-8.9)$ & 0.825 \\
\hline \multicolumn{5}{|l|}{ Location } \\
\hline Urban & $68(19.9 \%)$ & $56(18.7 \%)$ & $12(27.9 \%)$ & \\
\hline Rural & $138(40.4 \%)$ & $122(40.8 \%)$ & $16(37.2 \%)$ & \\
\hline Not reported & $136(39.8 \%)$ & $121(40.5 \%)$ & $15(34.9 \%)$ & 0.366 \\
\hline
\end{tabular}

AKI: acute kidney injury; DBP: diastolic blood pressure (mmHg); GCS: Glasgow coma scale; HR: heart rate (bpm); LOS: length of stay in the ICU (days); SBP: systolic blood pressure $(\mathrm{mmHg})$; WBC: white blood cells; mean \pm standard deviation; median (interquartile range $25-75$ ). 


\begin{tabular}{|c|c|c|c|}
\hline Variable & $\begin{array}{c}\text { Urban } \\
\mathrm{n}=68(33 \%)\end{array}$ & $\begin{array}{c}\text { Rural } \\
\mathrm{n}=138(67 \%)\end{array}$ & $\mathbf{p}$ \\
\hline Age in years & $61 \pm 15.6$ & $62.1 \pm 16.1$ & 0.661 \\
\hline \multicolumn{4}{|l|}{ Sex } \\
\hline Male & $29(42.6 \%)$ & $59(42.8 \%)$ & \\
\hline Female & $39(57.4 \%)$ & $79(57.2 \%)$ & 0.988 \\
\hline Temperature $\left({ }^{\circ} \mathrm{C}\right)$ & $37.3(36.5-38.4)$ & $37.2(36.4-38.1)$ & 0.355 \\
\hline \multicolumn{4}{|l|}{ Temperature codified } \\
\hline$<36^{\circ} \mathrm{C}$ & $3(4.4 \%)$ & $16(11.6 \%)$ & \\
\hline $36-38^{\circ} \mathrm{C}$ & $45(66.2 \%)$ & $87(63 \%)$ & \\
\hline$>38^{\circ} \mathrm{C}$ & $20(29.4 \%)$ & $35(25.4 \%)$ & 0.235 \\
\hline SBP (mmHg) & $80(70-93)$ & $79(69.8-89.3)$ & 0.394 \\
\hline DBP (mmHg) & $46(40.3-50)$ & $47(40-52)$ & 0.655 \\
\hline HR (bpm) & $119(104.5-140)$ & $116(100.8-132)$ & 0.292 \\
\hline Total GCS & $14(10-15)$ & $14(9-15)$ & 0.385 \\
\hline Intubated status & 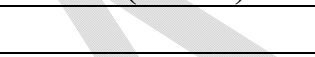 & 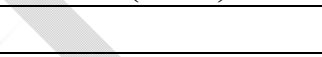 & \\
\hline Not intubated & $45(66.2 \%)$ & $92(66.7 \%)$ & \\
\hline Intubated & $23(33.8 \%)$ & $46(33.3 \%)$ & 0.944 \\
\hline WBC & $19.4(14.3-28.1)$ & $18.9(11.8-26)$ & 0.425 \\
\hline Creatinine $(\mu \mathrm{mol} / \mathrm{L})$ & $197(120.3-262.8)$ & $163(104.3-284)$ & 0.338 \\
\hline \multicolumn{4}{|l|}{ AKI } \\
\hline No AKI & $50(73.5 \%)$ & $98(71 \%)$ & \\
\hline $\mathrm{AKI}$ & $18(26.5 \%)$ & $40(29 \%)$ & 0.706 \\
\hline Charlson score & $2(0-3.8)$ & $2(0.8-3)$ & 0.791 \\
\hline LOS (in days) & $3.3(1.2-6.1)$ & $3.8(1.7-7.2)$ & 0.141 \\
\hline \multicolumn{4}{|l|}{ Mortality } \\
\hline Alive & $56(82.4 \%)$ & $122(88.4 \%)$ & \\
\hline Death & $12(17.6 \%)$ & $16(11.6 \%)$ & 0.233 \\
\hline
\end{tabular}

AKI: acute kidney injury; DBP: diastolic blood pressure (mm Hg); GCS: Glasgow coma scale; HR: heart rate (bpm); LOS: length of stay in the ICU (days); SBP: systolic blood pressure ( $\mathrm{mm} \mathrm{Hg}$ ); WBC: white blood cells; mean \pm standard deviation; median (interquartile range 25-75). 


\begin{tabular}{|c|c|c|c|c|c|c|}
\hline \multirow[b]{2}{*}{ Variable } & \multicolumn{3}{|c|}{ Univariable } & \multicolumn{3}{|c|}{ Multivariable } \\
\hline & OR & 95\% CI & $\mathbf{p}$ & OR & 95\% CI & $\mathbf{p}$ \\
\hline Age (1 year) & 1.005 & $0.984-1.027$ & 0.617 & 0.999 & $0.974-1.024$ & 0.908 \\
\hline \multicolumn{7}{|l|}{ Sex } \\
\hline Male & 1 & & & 1 & & \\
\hline Female & 0.567 & $0.298-1.078$ & 0.083 & 0.495 & $0.231-1.061$ & 0.071 \\
\hline \multicolumn{7}{|l|}{$\begin{array}{l}\text { Temperature } \\
\text { codified }\end{array}$} \\
\hline $36-38^{\circ} \mathrm{C}$ & 1 & & & 1 & & \\
\hline$<36^{\circ} \mathrm{C}$ & 4.000 & $1.661-9.634$ & 0.002 & 2.357 & $0.820-6.778$ & 0.111 \\
\hline$>38^{\circ} \mathrm{C}$ & 1.133 & $0.540-2.374$ & 0.741 & 0.843 & $0.352-2.018$ & 0.701 \\
\hline SBP $(1 \mathrm{mmHg})$ & 0.996 & 0.984-1.009 & 0.561 & 1.000 & $0.987-1.013$ & 0.963 \\
\hline HR (1 bpm) & 1.009 & $0.998-1.020$ & 0.097 & 1.009 & $0.997-1.021$ & 0.138 \\
\hline \multicolumn{7}{|l|}{ Intubated status } \\
\hline Not intubated & 1 & & 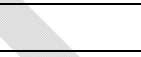 & 1 & 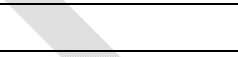 & \\
\hline Intubated & 4.330 & $2.212-8.478$ & $<0.001$ & 5.005 & $1.945-12.878$ & 0.001 \\
\hline WBC $(g / L)$ & 0.973 & $0.945-1.002$ & 0.069 & 0.971 & $0.943-0.9999$ & 0.0497 \\
\hline \multicolumn{7}{|l|}{ AKI } \\
\hline No AKI & 1 & 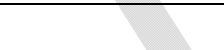 & 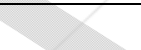 & 1 & & \\
\hline AKI & 4.928 & $2.536-9.577$ & $<0.001$ & 4.620 & $2.103-10.150$ & $<0.001$ \\
\hline $\mathrm{CCI}$ & 1.103 & $0.965-1.261$ & 0.151 & 1.076 & $0.915-1.267$ & 0.375 \\
\hline LOS (1 day) & 1.008 & $0.995-1.022$ & 0.207 & 1.003 & $0.989-1.018$ & 0.668 \\
\hline \multicolumn{7}{|l|}{ Location } \\
\hline Urban & 1 & 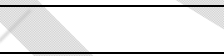 & s & 1 & & \\
\hline Rural & 0.612 & $0.272-1.379$ & 0.236 & 0.477 & $0.183-1.244$ & 0.130 \\
\hline Not reported & 0.579 & $0.254-1.317$ & 0.192 & 1.228 & $0.407-3.701$ & 0.716 \\
\hline
\end{tabular}

AKI: acute kidney injury; CI: confidence interval; HR: heart rate (bpm); LOS: length of stay in the ICU (days); OR: odds ratio; SBP: systolic blood pressure (mmHg); WBC: white blood cells. 